\title{
Using family Resources as a Coping StRATEgy \\ to Manage Stress During the COVID-19 Pandemic
}

\author{
By \\ Mai Elsoilah \\ Kuwait
}

Research Gournal Specific Fducation

Faculty of Specific Fducation

gYansoura University

ISSUE NO. 64, OCTOBER, 2021

مجلة بعوث التربية النوعية - جامعة المنصورة

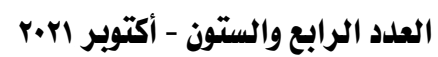




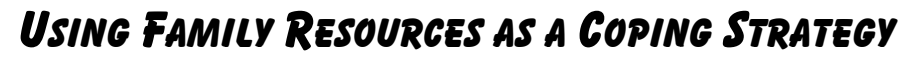 \\ to Manage Stress During the COVID-19 Pandemic}

\section{Mai Elsoilah*}

\section{Abstract}

This paper draws on the resiliency model of family stress, adjustment and adaptation and explores the use of family resources as a coping strategy to manage stress during the COVID-19 pandemic in a subset of Kuwaiti women. A mixed methods research design was used for collecting, analysing and integrating survey and interview data, The most common stressors were social isolation, quarantine and lockdown measures, fear of contagion, increased workload, and fear of shortage of basic needs. The results showed that the Kuwaiti women adopted strategies to cope with stress on three levels: macro-social, relationship, and personal. Quantitative results indicate a significant difference in coping styles between married and unmarried women, especially with regard to positive reframing and passive appraisal. The interviews yielded important new insights such as the important role of social relationships and social support, religious beliefs, personal attitude (active coping) negative emotions (passive coping), and family socialisation and togetherness. Findings also suggest that social support as well as family cohesion and hardiness contributed to increased stress resiliency. This study makes a significant contribution to literature as little research has examined the use of family resources to cope with stress during the pandemic.

Key words: family stress, resilience, family resources, coping strategies, women and COVID-19, pandemic, family crisis oriented personal evaluation scale. 


\section{Introduction}

\subsection{Background}

Coronavirus or COVID-19 and the impacts of the lockdown has brought about drastic changes in family life (Al Dhaheri et al., 2021; Shuwiekh et al., 2020; Wang, 2020). The pandemic has been disruptive and has changed the way in which we perform our daily activities and go about our routine lives (Chauhan, 2020). From a psychological perspective there is a considerable uncertainty about quarantine duration and loss of control which has triggered stress and emotional distress (Janssen et al., 2020; Mosanya, 2020). Research has increasingly highlighted the impact of the pandemic on social, psychological, and emotional well-being (Garbóczy et al., 2021; Kubb \& Foran, 2020; Saravanan et al., 2020).

At the family level, the pandemic has imposed stress on the family members as they are forced to re-organise everyday life (Fegert et al., 2020; Spinelli et al., 2020). It has made the living environment more difficult and amplified the roles and responsibilities of family members as they are faced with more daily hassles and additional tasks (Janssen, et al., 2020; Wang, 2020). School closures have led to distance or remote learning which in turn has affected child and youth learning causing academic distress (Mosanya, 2020). Parents are experiencing increased pressure as they have to not only work from home, but also take responsibility for home-schooling children (Fegert et al., 2020). Furthermore, the lack of services of domestic workers in both developed and developing nations has forced women to spend more time on household chores than before (Chauhan, 2020; Del Boca et al., 2020). For instance, shopping for food has become a challenge now with social distancing as they have to take more precautions so as to not contract the virus. Consequently, this has put undue pressure on women and increased their drudgery (Chauhan, 2020). Thus, all family members have to cope with the stress during the quarantine.

The present study aimed to investigate the stress and coping strategies of Kuwaiti families during the COVID-19 pandemic. It examines how families are coping with stress by using family resources and making 


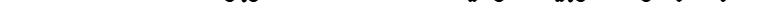

adjustments over time following the pandemic. Research claims that psychological distress among women has heightened during the pandemic as they are most likely to stay home, do household chores and take care of children (Alsharji, 2020; Wenham, Smith \& Morgan, 2020). Therefore, the perceptions of women are important for understanding the use of family resources as a coping strategy to manage stress in a crisis or stressful situation.

\subsection{Rationale}

Previous research has uncovered a wide range of coping strategies used by people during the pandemic and has focused mainly on healthcare workers (Tahara, Mashizume \& Takahashi, 2021; Shechter et al., 2020), people with cancer and chronic diseases (Galica et al., 2021), students (Garbóczy et al., 2021; Cao et al. 2020; Saravanan et al., 2020) and gender differences in perceptions of stress (Yan et al., 2021). However, the literature on the coping strategies of women during the current pandemic is scarce. Moreover, studies exploring the use of family resources as a coping strategy to manage stress have not been carried out in Kuwait or in GCC. This paper adds to our understanding of how the effects of family resources and family-centered practices can help ameliorate stress during the COVID19 pandemic. Guided by the resiliency model of family stress, adjustment and adaptation, this study identifies COVID-19 related stressors (for example, the infectious nature of COVID-19 or fear of contagion, increased workload, and separation from society) at the family level, and further elaborates on how family resources can serve as a coping strategy to manage stress.

The research questions addressed are:

(1) What coping strategies are families using to manage stress during the COVID-19 lockdown in Kuwait?

(2) How are the families using family resources as a coping strategy to deal with stress?

This paper encompasses five sections. The first section provides the background and rationale for the study. The second section reviews the 
literature and presents the theoretical framework. The third describes the methodology adopted to address the research questions. The results are presented in the fourth section while the fifth discusses the findings. The last section summarises the conclusions and discusses the implications as well as the limitations of this study.

\section{Literature review}

A review of existing literature was undertaken on topics that were relevant and specifically related to coping strategies adopted by families to manage stress when faced with unprecedented life events. The review involved selecting latest empirical studies from 2020 or later with some dating earlier. However, care was taken to include only articles that align with the current study's focus and research questions. Most journal articles were peer-reviewed and specific to the field of family stress, coping strategies, COVID-19, and family resource management. The descriptors that were used for searching and locating the articles included 'family stress', 'resilience', 'family resources', 'coping strategies', 'COVID-19', 'pandemic', and 'Family Crisis Oriented Personal Evaluation Scales'.

\subsection{Family Stress}

Family stress is defined as a stressor or disruption in the stable equilibrium or healthy functioning of the family system (Boss, 2014; Randall \& Bodenmann, 2013). The beliefs family members hold about stress play a key role in shaping how they cope with stress (Scult et al., 2017). In the context of this study, the pandemic is the stressor or the disturbance which is causing a change in the family's coping pattern. In Kuwait and other Arab states, travel restrictions, school and business closures, social distancing, isolation, and fear of shortage of basic needs have had an impact on mental health and quality of life resulting in traumatic stress (Al Dhaheri et al., 2021; Shuwiekh et al., 2020).

While steps taken to prevent the spread of the COVID-19, including lockdown, physical and social distancing, and curfew, may be critical to extenuating its spread, the measures are said to have negative consequences 


\section{.}

on mental health (Cao et al. 2020; Mosanya, 2020). Social distancing procedures, restrictions on movement and isolation have reduced social interaction and impeded much needed social support, leading to stress, feeling helpless and social isolation (Mosanya, 2020). Research suggests that stress increases with lack of social support, isolation, and seclusion (Wang et al. 2020).

Recent studies have revealed that the current COVID-19 lockdown has impacted social and physical activity and increased screen times, irregular sleeping habits, improper diets, intolerance of uncertainty caused by negative beliefs about the pandemic and rapid mood swings (Alsharji , 2020; Janssen, et al., 2020; Pisano, Galimi \& Cerniglia, 2020). Parents, on the other hand, have been reported as worrying about their ability to provide income for their families, experiencing general stress and feelings of tiredness, having difficulties in their relationships and with managing children's academic pursuits, and suffering from poor mental and physical health (Brown et al., 2020). Although the pandemic was unexpected and catastrophic, families are using their coping strategies and resiliency, in order to withstand the pressure and become stronger.

\subsection{Family Resources and Coping Strategies to Manage Stress}

Coping involves relying on family and self-resources and strategies to manage stress (Berardi, Glantsman \& Whipple, 2019; Martínez-Montilla, Amador-Marín \& Guerra-Martín, 2017). Coping in the context of this paper is defined as a set of family resources that a family member uses to deal with problems, to respond to or recover from difficult circumstances created by the pandemic, and to lessen the strains, for instance by preventing, avoiding, or controlling emotional distress. Family resources refer to the internal capacity and characteristics of a family that safeguard the family from the effect of stressors and enable the family to adapt to stress and the crisis (Price, Price \&, McKenry, 2020). Thus, family coping is a process that involves family cohesion and adaptability or ability to change.

It is claimed that resilience can enhance positive coping (Wu et al., 2020; Walsh, 2016). Family resilience is a family's capability to cope with 
living by maintaining a cohesive family, by lessening the stressful impact of a situation through an interpersonal or social process as well as by identifying and accessing resources over time in order to return to pre-crisis situation quickly (Wu et al., 2020; Henry et al., 2018; McCubbin \& McCubbin, 1996). Examp Resiliency is a defense mechanism that involves management of stress using social support and moderating harmful effects (Harris, Greene \& Chavez, 2019). Overall, resilient coping refers to managing stress in a highly adaptive manner (Kocalevent et al. 2017). Research demonstrates that coping with stress builds resilience and that higher resilience is due to better awareness of the stressor and operationalizing personal resources to face unprecedented life events (Faccio et al., 2018; Kocalevent et al. 2017). Personal resources include qualities or attributes of a person, such as dispositional coping style or habitual ways of dealing with stress, for instance friendliness, conscientiousness, and sociability (Galica et al., 2021).

Families use constructive or practical coping strategies to manage a stressful situation, such as positive thinking by acquiring social support, mobilizing family and friends to acquire support, and seeking spiritual support (Cao et al. 2020; Mosanya, 2020; Zhang and Ma 2020; MartínezMontilla et al., 2017). Social support, which can be accessed through social ties, is an adaptive problem-focused strategy (Mosanya, 2020). It involves exchange of information by individuals and providing emotional support. Families acquire social support through social networks such as places of worship, friends, and extended family or through more health care or educational institutions (Mariani et al., 2020; Salin et al., 2020; Lorenz et al., 2019). Research shows that close friends and social relationships can play a great role in dealing with stress and anxiety caused by the pandemic (Mosanya, 2020). Some families may also use negative coping strategies, such as the use of passive coping or maladaptive strategies that include avoidance behaviours and negative thinking (Liu, Reed \& Vickers, 2019; Little, 2018; Liu et al., 2017; Wood \& Bhatnagar, 2015). Researchers claim that maladaptive strategies are associated with stress while adaptive strategies are linked to life satisfaction (García). 
The use of positive cognitive framing or restructuring is also noted to be an emotion-focused coping strategy (Larsson, Hooper \& Osborne, 2016). It involves proactive behaviour as individuals adjust attempt to change their viewpoints of the stressful event or experience and see it in a more positive light as against engaging in negative thoughts. Through reframing, individuals can control the way they react to unexpected situations, for example by accepting stressful events as a fact of life and believing that one has the power or the strength to handle the situation. Psychological researchers claim that positive reframing can make the stressor experience to be less stressful. (Liu et al., 2019; 2017).

Acceptance is another emotion-focused coping strategy that family members may utilize to cope with the family members and relatives. Acceptance is a form of cognitive restructuring where individuals appraise their thinking, react and change negative reactions to positive, or at least neutral ones (Polizzi et al., 2020). Research has demonstrated that incorporating acceptance in one's life can lessen stress and improve their relationship with family members (Levin et al., 2020). Prior research also shows that interventions that promote acceptance, such as mindfulness, may mitigate general stress and fortify resilience (Polizzi et al., 2020). Mindfulness is the practice of observing and engaging with a situation without judging or reacting to it (Polizzi et al., 2020), for example listening to music or meditation exercises. However, recent studies have proven that acceptance is not positively associated with perceived stress (Brown et al., 2020; Donald \& Atkins, 2016). Another study that examined coping strategies during the COVID-19 pandemic in Canada found that positive reframing was the most effective and that acceptance did not have a significant effect on stress (Shamblaw, Rumas \& Best, 2021). The study suggests that interventions focusing on reframing negative aspects of the pandemic may be most beneficial to mitigate stress.

Family members also mobilise family resources to cope with the pandemic. These resources include values, communication and interaction skills, social support, physical and financial resources (Martínez-Montilla, AmadorMarín \& Guerra-Martín, 2017). Recent research from suggests that family 
bonding time, social gatherings, family conversations, strong family relationships and sharing information about their thoughts and feelings can strengthen families and protect them from stressful situations (Friedline, Chen \& Morrow, 2020; Mariani et al., 2020; Salin et al., 2020; Liu et al., 2019; Liu et al., 2017). There is evidence that during the pandemic, family relationships acted as a buffer against stress, and individuals who received increased family support and social support from friends and family members were less likely to develop anxiety (Mosanya, 2020; Zhang \& Ma, 2020). These results were confirmed by Mariani et al., (2020) who also found that family support can reduce the sense of loneliness. Ogueji, Okoloba \& Demoko Ceccaldi, (2021) investigated the coping strategies of 50 individuals in the UK. The qualitative study found that the participants engaged in meditation, regular exercises, physical activities, immersed in their jobs, concentrated on studies, avoided negative news about the pandemic, maintained a healthy eating lifestyle, indulged in gaming, stayed hopeful, and practiced self-care and self-appreciation. These results corroborate previous research (for example Alsharji, 2020; Williams et al. 2020, Salin et al., 2020) which submitted that keeping oneself busy with work or learning, or other social activities and engaging in physical exercises and meditation has the potential to reduce stress. This suggests that family members are indispensable in dealing with the pandemic situation.

Another important aspect to emphasize is that culture, for example religion and faith, plays a crucial role when families are coping with stressful events (Friedline et al., 2020; Martínez-Montilla et al., 2017; Barrett, 2013). Religion is also one of the major elements of social support and may moderate the negative effects of stress (Lorenz et al., 2019), Seeking spiritual support is seen as a positive emotion-focused coping strategy and includes faith and religious beliefs (Tobe et al., 2016). Therefore, religion and spirituality are cultural and psychological resources that families can use for managing stress.

Passive appraisal or passive coping is a maladaptive strategy which some individuals use to mentally detach themselves from stressful situations 
(Wood \& Bhatnagar, 2015). Example of passive coping strategies are escaping, avoiding, substance use, venting, and refusing to believe in the stressor (Little, 2018). Families use this negative strategy to misjudge the threat of the pandemic or underestimate their own coping ability. They try to minimize the outcome of the pandemic by watching television and hoping that they will be lucky and may not contract the virus.

\section{Theoretical framework:}

This paper integrates family resource management with the Resiliency Model of Family Stress, Adjustment and Adaptation to address the impact of COVID-19 pandemic which has become a socially relevant issue.

The Resiliency Model of Family Stress, Adjustment, and Adaptation developed by McCubbin and McCubbin (1996) is used in his study to describe how individuals are adapting despite adverse circumstances by using their resources. McCubbin, Olson \& Larsen (1991) posited that people with more coping behaviours will be able to better adapt to stressful situations than those with inadequate coping behaviours. McCubbin and McCubbin (1996) also theorized that family hardiness is a family resource which can help in making the family resilient. Hardiness is an attitude that families have to persevere, to actively adapt to the stressful situation, and the confidence to endure challenges (McCubbin, McCubbin, \& Thompson, 1987). Family hardiness is claimed to help family members cope, endure, and actively engage in transformational coping in order to perceive the stress as an opportunity rather than a menace (Mosley \& Laborde, 2015).

Family resources include personal and physical resources (such as money, education, and emotional aspects), social and community support (such as extended family members, colleagues at work and community), and resiliency resources (such as inherent abilities of the individual family members to adapt, family cohesion and hardiness). According to McCubbin et al. (1991), family resources predict how a family adapts to stressful events. This suggests that personal resources, social support, and family system resources are linked with family resiliency. 
The resiliency model of family stress, adjustment and adaptation is used in this study as it provides a strength-based view of a family or where the family is viewed as capable (Walsh, 2016). The resiliency model and family resource management are integrated to explain why some individuals are resilient, have the capabilities to use available resources to influence the resilience of other family members, and support the family to recover from a crisis.

\section{Methodology}

A cross-sectional mixed methods study design was used to analyse data collected from a defined population to assess the coping strategies or problems that are unique to this specific period. The rationale for using this research design was to describe a population of interest, namely Kuwaiti women, and to understand the prevalence of a phenomenon (namely prevalence and sources of stress) without manipulating variables (Wang \& Cheng, 2020; Allen, 2017). This study is not causal as the intention is not to determine cause and effect relationship between two variables but to explain the circumstances and context of the cause (Loeb et al., 2017).

\subsection{Instruments}

The Family Crisis Oriented Personal Evaluation Scales (F-COPES), an ethnically sensitive measure developed by McCubbin, Olson, and Larsen (1991), was used to identify strategies adopted by Kuwaiti women to cope with stress. The survey instrument draws upon the coping dimensions of the Resiliency Model of Family Stress, Adjustment and Adaptation developed by McCubbin and Associates (McCubbin et al., 1991; 1996; 1998). FCOPES consists of 30 self-report items and is distributed over five scales: acquiring social support (10 items), positive reframing (8 items), seeking spiritual support (4 items), mobilizing the family to acquire support (4 items), and passive appraisal (4 items). The 5-point scale ranges from 1 to 5 (Strongly Disagree=1; Disagree $=2$; Neither Agree nor Disagree=3; Agree $=4$; Strongly Agree=5).

Reliability was demonstrated with Cronbach's alpha coefficient of 0.61 for the entire scale. Construct validity was evaluated by known groups. 
The self-report F-COPES scale was used on this study to record the how Kuwaiti women and their families are responding to and coping with the stress caused by the pandemic. The responses to the questionnaire items were used to guide the interview protocol. Interviews were used to thoroughly characterise and describe the coping strategies used by the participants. The rationale for using interviews is that existing questionnaires do not help in characterizing and describing the coping strategies adopted by people in stressful situations like the COVID pandemic (Wasil et al., 2021). The semi-structured interview consists of four open-ended questions:

(a) How are you adapting to the new normal? How are you coping with difficulties?

(b) What coping strategies or protective practices are you using to manage stress?

(c) What support systems are you using to cope with your family members?

(d) What resources do you have or would like to have to help you cope with your family members?

All interviews were conducted via Zoom and the audio was digitally recorded. Field notes were also created to supplement the interview data. Probes and cues were used to elicit facts or statements from the interviewees. Interviews ranged between 15 and 30 minutes. All responses were transcribed verbatim, and pseudonyms were used to conceal the identity of the interviewees.

\subsection{Sample}

In March (2021), an anonymous online questionnaire was circulated via a commonly used social media platform in Kuwait. Two hundred and ten questionnaires were returned. Interestingly all were from women. However, only 150 questionnaires were fully completed. Most of the women were between 21 and 25 years of age. The sample consisted of 87 married women (58\%) and 63 unmarried women (42\%). Most of them had 
university degrees and were relatively young (21-25 years). Fifteen women agreed to take part in the interviews.

Table 1 Demographic characteristics of the sample

\begin{tabular}{cccc}
\hline \multicolumn{2}{c}{ Characteristics } & $\begin{array}{c}\text { Survey } \\
\text { Frequency }\end{array}$ & $\begin{array}{c}\text { Interview } \\
\text { Frequency }\end{array}$ \\
\hline \multirow{2}{*}{ Marital status } & Married & $87(58 \%)$ & 8 \\
Education & Unmarried & $63(42 \%)$ & 7 \\
level & School & 11 & 1 \\
Age groups & University degree & 139 & 14 \\
(in years) & $21-25$ & 106 & 6 \\
& $26-30$ & 32 & 8 \\
\hline
\end{tabular}

\section{Results}

\subsection{Quantitative Results}

The first objective of this study sought to identify the coping strategies adopted by families to manage stress during the COVID-19 lockdown in Kuwait. The collected data was entered and analysed using SPSS version 19 on measures of central tendency. Tables 2 describes these findings. 
Table 2 Descriptive statistics: Coping strategies adopted by married and unmarried women to manage stress

\begin{tabular}{|c|c|c|c|c|c|}
\hline \multicolumn{2}{|r|}{ Items } & \multicolumn{2}{|c|}{ Married } & \multicolumn{2}{|c|}{ Unmarried } \\
\hline & & M & $\mathrm{SD}$ & M & $\mathrm{SD}$ \\
\hline & Acquiring Social Support & & & & \\
\hline 1 & Sharing our difficulties with relatives & 4.15 & 0.93 & 3.46 & 1.04 \\
\hline 2 & Seeking encouragement and support from friends & 4.20 & 0.87 & 4.08 & 0.75 \\
\hline 3 & Seeking advice from relatives (grandparents, etc.) & 4.03 & 0.84 & 4.34 & 0.69 \\
\hline 4 & Sharing concerns with close friends & 4.08 & 1.17 & 4.08 & 0.84 \\
\hline 5 & Sharing problems with neighbours & 3.91 & 1.03 & 3.41 & 1.16 \\
\hline 6 & Asking neighbours for favours and assistance & 3.86 & 1.01 & 3.51 & 1.14 \\
\hline 7 & Receiving gifts and favours from neighbours & 3.78 & 0.93 & 3.83 & 0.75 \\
\hline 8 & Doing things with relatives (get-together, dinners, etc.) & 4.29 & 0.93 & 4.17 & 0.50 \\
\hline 9 & Asking relatives how they feel about problems we face & 3.60 & 1.21 & 4.32 & 0.63 \\
\hline \multirow[t]{2}{*}{10} & Exercising with friends to stay fit and reduce tension & 4.22 & 0.91 & 4.24 & 0.70 \\
\hline & Positive Reframing & & & & \\
\hline 11 & Knowing we have the power to solve major problems & 3.98 & 1.01 & 4.07 & 0.45 \\
\hline 12 & Knowing that we have the strength within our family to solve our problems & 3.97 & 1.02 & 4.24 & 0.77 \\
\hline 13 & Facing the problems "head-on" and trying to get solution right away & 4.33 & 0.76 & 4.29 & 0.64 \\
\hline 14 & Showing that we are strong & 4.10 & 1.12 & 4.54 & 1.12 \\
\hline 15 & Believing we can handle our own problems & 4.26 & 0.93 & 4.41 & 0.81 \\
\hline 16 & Defining family problem in a more positive way so as to not get too discouraged & 3.80 & 1.14 & 3.69 & 0.62 \\
\hline 17 & Accepting stressful events as a fact of life & 3.74 & 0.95 & 4.29 & 0.64 \\
\hline \multirow[t]{2}{*}{18} & Accepting that difficulties occur unexpectedly & 3.59 & 1.05 & 4.49 & 0.95 \\
\hline & Seeking Spiritual Support & & & & \\
\hline 19 & Having faith in God or a higher power & 4.57 & 0.50 & 4.51 & 0.50 \\
\hline 20 & Seeking advice from a spiritual leader & 4.16 & 0.79 & 4.56 & 0.60 \\
\hline 21 & Participating in religious or spiritual activities & 4.32 & 0.81 & 4.49 & 0.57 \\
\hline \multirow[t]{2}{*}{22} & Listening/Attending religious services & 4.23 & 0.74 & 4.31 & 0.56 \\
\hline & Mobilizing Family to Acquire Support & & & & \\
\hline 23 & $\begin{array}{l}\text { Seeking information and advice from person in other families who have faced the same or } \\
\text { similar problems }\end{array}$ & 4.00 & 1.00 & 4.46 & 0.65 \\
\hline 24 & Seeking assistance from community agencies and programs & 3.18 & 1.25 & 3.75 & 1.11 \\
\hline 25 & Seeking professional counselling and help for family difficulties & 3.80 & 1.05 & 4.41 & 0.91 \\
\hline \multirow[t]{2}{*}{26} & Seeking information and advice from the family doctor & 3.93 & 1.14 & 4.37 & 0.55 \\
\hline & Passive Appraisal & & & & \\
\hline 27 & Watching television & 3.93 & 0.83 & 3.92 & 0.75 \\
\hline 28 & Knowing luck plays a big part in solving family problems & 3.79 & 1.04 & 4.31 & 0.81 \\
\hline 29 & Feeling that no matter what we do to prepare, we will have difficulty handling problems & 3.71 & 1.01 & 4.56 & 0.57 \\
\hline 30 & Believing if we wait long enough, the problem will go away & 3.00 & 1.56 & 4.31 & 0.88 \\
\hline
\end{tabular}


The family members' coping strategies were estimated based on the weighted mean of the five scales. Interestingly, the mean scores of unmarried women suggest that they were able to cope with stress much better than married women. Table 2 shows that married women were able to cope with stress only by acquiring social support $(\mathrm{M}=4.01)$ whereas unmarried women were able to manage stress through positive reframing $(\mathrm{M}=4.25)$, seeking spiritual support $(\mathrm{M}=4.47)$, mobilizing family to acquire support $(\mathrm{M}=4.25)$ and passive appraisal $(\mathrm{M}=4.27)$. It also indicates that married women were more stressed than unmarried women.

Independent-samples t-tests were conducted to compare coping strategies adopted by married and unmarried women (Table 3).

Table 3. Coping strategies according to marital status

\begin{tabular}{cccccc}
\hline \multirow{2}{*}{ Scales } & $\begin{array}{c}\text { Marital } \\
\text { status }\end{array}$ & Mean & $\mathrm{t}$ & df & Sig.(2- tailed) \\
\hline Acquiring Social Support & Married & 4.01 & 0.499 & 15 & 0.62 \\
& Unmarried & 3.94 & & & \\
Positive Reframing & Married & 3.97 & -2.124 & 14 & 0.05 \\
& Unmarried & 4.25 & & & \\
Seeking Spiritual Support & Married & 4.32 & -1.358 & 5 & 0.23 \\
& Unmarried & 4.47 & & & \\
Mobilizing Family to Acquire Support & Married & 3.73 & -2.057 & 6 & 0.08 \\
& Unmarried & 4.25 & & & \\
Passive Appraisal & Married & 3.61 & -2.681 & 5 & 0.04 \\
& Unmarried & 4.27 & & & \\
\hline
\end{tabular}

The t-test results showed that there were significant differences between married and unmarried women with regard to their positive reframing and passive appraisal $(\mathrm{p}<0.05)$. This suggests that the null hypothesis is rejected. However, for the other three scales (acquiring social support, seeking spiritual support, and mobilizing family to acquire support) the significance was found at the .05 or .01 level, and the results for these scales suggest that the married and unmarried women were not that different in their responses. 


\subsection{Qualitative themes}

The interviews were analysed using inductive thematic analysis with a phenomenological lens. The data was read, re-read, coded, and categorized resulting in 5 themes: negative emotions, personal attitude, religious beliefs, family socialisation and togetherness, and social relationships and social support.

The theme 'negative emotions' was generated from the responses to the question about the source or cause of stress. Though all women were asked specific questions about dealing with the pandemic, some respondents made mention of frustration prior to being prompted to do so.

We had expectation that everything would return back to normal, but we are disappointed. (W1)

We are unable to do everything we did before. It is worrying. (W3)

I am frustrated. This is going on for long. It's more than a year and I don't see any hope. (W4)

I am worried about my children and grandparents and the health of others in the family. (W11)

The informants were frustrated as they were not able to live like before. They had high expectations that the situation would change. Instead, the pandemic proved to be a psychological stressor that challenged their adaptive capabilities and resources. Therefore, they displayed negative emotions.

'Personal attitude' is another theme which is related to hardiness. It includes personal time. While the majority of the women reported that they were experiencing psychosocial stress, some expressed that they were able to see a silver lining. When probed, one informant replied that:

News about the vaccines is giving me hope. Moreover, I am a survivor. I will move forward. I don't want to give up. (W2)

Other informants also expressed similar sentiments: 
I keep thinking about how such a thing happened and I am unable to understand it. I was so worried initially, but I have come out of the rut. (W5)

Doing household chores and taking care of my family makes me feel like I have a purpose, it is who I am. (W7)

The women also used cognitive approaches or positive cognitive reframing to change their views about the pandemic.

I have attempted to change my expectations to match reality. (W8)

Sometimes I feel depressed or unhappy. I try to talk to my inner feelings, that it is not as bad as everyone thinks it is. (W8)

I won't see this pandemic as a threat but as a challenge. (W12)

One informant who adopted active coping claimed:

I want to help others and see how my own efforts can benefit others. (W6)

The following are related to personal time and are examples of mindfulness geared to decrease stress and promote resilience:

I work from home as I am a blogger. It helps me engage in jobrelated activities which keeps me distracted from the pandemic. (W7)

I always take care of myself. I cook and eat healthy meals. (W7)

I exercise and get plenty of sleep. (W10)

I play chess with the kids if I feel stressed out. (W12)

The aforementioned quotes emphasize the spatial and temporal nature of the pandemic. The women were using their internal strengths and demonstrating that they had a sense of control over the outcomes of the pandemic in spite of the adversities. Overall, they had not only adjusted to the pandemic but were able to manage the stressful situation

The third theme that emerged was 'religious beliefs'. Religion, as a source of moral norms and beliefs, is a macro-social force. Religious beliefs were often mentioned as helpful by almost all the informants: 
Inshallah. We are managing and we will contain this virus as God will help. I pray daily. (W3)

I look to God for strength. So, I am able to accept the uncertainty and challenges we are facing. (W4)

The religious beliefs provided emotional comfort for the women.

'Family socialisation and togetherness' was the overarching theme generated from the interview transcripts. Family time and communication were often cited by the women. According to them, family interaction, one of the family resources, helped moderate the impact of the stressor. The participants explicitly referred to the helpfulness of family patterns, such as cohesiveness:

It's amazing how our family got together and got stronger. (W7)

The following responses suggest that healthy, supportive families are crucial forgetting through these tough times:

We verbally complement one another. We express gratitude to our family members. (W5)

I know that it is devastating. However, I encourage family members. (W5)

I pay utmost attention to my children and spouse. (W8)

We keep a time-table and everyone's responsibilities are clear as to who should do what and when. (W14)

The women claimed that immediate as well as extended family members also provided support.

The members of my family as well as that of my husband really help and support us. (W10)

At times, my child feels lonely as he is unable to play with friends.

However, there is also a feeling of closeness in our family because we spend time together often. This helps in this situation. (W14)

Interestingly, six informants who recounted that there was tension or conflict with their extended family also reported that family members were a source of support for them. Following are some excerpts: 
Although our family is large, I am happy that they support us. (W8) We have problems within the family, as there are feelings of loneliness among some. But we helped by put those feelings aside through family and decided as this situation is more important, and we have to stay together. (W12)

Similarly, two informants mentioned siblings provided support:

My brother really was extraordinary... he called me and my mother regularly and visited us. The bond that formed between us was incredible. (W7)

Other informants cited strong marital relationship as a valuable factor.

We communicate and spend alone time together. (W12)

We have an open mind and understand our roles. We agree what each one has to do on a daily basis. (W14)

It is evident from the aforementioned quotes that there was emotional bonding. The women talked about their experiences and ways in which they dealt with difficulties. They reported that family members assisted each other and worked as a unit to maximize resources and reduce risks.

The fifth theme 'social relationships and social support' suggests that the women received social support from a network of friends, neighbours and the wider community. This support was an emotional and physical resource that helped individuals to cope with stress. As one participant indicates:

The pandemic hasn't been that hard for me as compared to others who had no one to turn to or had close friends or neighbours to rely on. (W8)

One of the cognitive processes included the use of comparative coping whereby the women compared their stress with friends and neighbours in order to control stress:

I not only share my thoughts about ways of dealing with the lockdown with family members, friends and neighbours but also learn from their experiences. (W8) 
By engaging with others, I am able to replace my thoughts with more positive ideas. (W10)

In this way the women were able to identify negative interpretations of the pandemic that are unrealistic and replace them with more accurate and rational explanations. The women also reported that seeking information and support from others was particularly important as a means of coping with stress. Overall, the informants sought emotional support from a variety of sources. Some sought help from trusted people in the community. Health care services and friends within the community were identified as key sources.

One method for making the situation more manageable was through increasing awareness and knowledge by gathering information about the stressor. The women used information seeking practices in order to reduce the impact of a stressor.

I keep checking with community and government-provided social support for information about dealing with the virus. (W10)

Yes, I am receiving social support. I have caring close friends and family members who provide hope. (W13)

My friends give me informational advice, suggestions, and information. (W14)

The strategy was using information and support to enhance awareness in order to overcome fear. For them, the information helped quell concerns regarding the source of stress.

\subsection{Triangulation}

The multiple methods or data sources were triangulated. Then appropriate themes identified in the qualitative analysis were compared with quantitative results. 
- Using Family Resources as a Coping Strategy to Manage Stress During the COVID-19 Pandemic

Table 4 Comparison of quantitative and qualitative data

\begin{tabular}{cc}
\hline Quantitative constructs & Qualitative themes \\
\hline Acquiring Social Support & Social relationships and social support \\
Positive Reframing & Personal attitude \\
Seeking Spiritual Support & Religious beliefs \\
Mobilizing Family to Acquire Support & Family socialisation and togetherness \\
Passive Appraisal & Negative emotions \\
\hline
\end{tabular}

The qualitative descriptions of the women reflected their use of coping resources from the family system, which aligned with the strategies identified in the descriptive data. The results from the data sets are combined and interpreted in discussion.

\section{Discussion}

This study explored the use of family resources as a coping strategy to manage stress during the COVID-19 pandemic in a subset of Kuwaiti women. Family resource management and the Resiliency Model of Family Stress, Adjustment and Adaptation were integrated to address the impact of the pandemic on stress. The results showed that the Kuwaiti women adopted strategies to cope with stress on three levels: personal, macro-social and relationship or group-level coping strategies.

Personal level strategies included the use of personal resources to maintain a positive attitude and by using time appropriately. The women had developed qualities that formed the core of their personal adaptive potential. They adopted active coping strategies such as cooking and eating healthy meals, getting plenty of sleep, playing chess, and engaging in jobrelated activities. In doing so, the women demonstrated that they were able to understand and reframe unrealistic expectations through mindfulness, for example meditation and physical exercises. Prior research has documented that mindfulness is a personal level coping strategy and can strengthen resilience (Ogueji et al., 2021; Alsharji, 2020; Polizzi et al., 2020; Salin et al., 2020; Williams et al. 2020). The use of personal resources suggests that they wanted to stay hopeful. The dispositional coping styles of the women also indicate that there was a sense of control and commitment which is 
associated with hardiness which is a family resource (Mosley \& Laborde, 2015). They used this transformational coping strategy to reframe the stressful condition they were in. Overall, the results show how cognitive frames had elicited positive emotions and aided active/pro-active coping.

Both the survey and interview data revealed that some participants used passive coping strategies or passive appraisal. Participants passively viewed the situation by displaying negative emotions, for instance watching television, depending on luck and that they will not be able to handle the problems. During the interviews, some women expressed negative emotions. They showed signs of helplessness. They internalized negative aspects of the pandemic.

This study also found a significant difference in coping styles between married and unmarried women, especially with regard to positive reframing and passive appraisal. The present study contributes to the existing research by revealing a difference in the coping style between married and unmarried women. A possible explanation for the difference may be related to differences between them in the knowledge and skills of coping strategies for stress associated with the pandemic.

The women claimed that their families had adequate resources for meeting the demands of this ongoing global stressor, especially the capacity to adapt to change. The women reported that their families used varied resources to handle stress which included communication, the capability to take on the pandemic, and taking advantage of social support networks. These macro-social level strategies also included religious beliefs.

The multifaceted experiences of the women suggest that they were using rapport building and used technology-enabled interaction to maintain connections. The participants perceived that maintaining social support during the pandemic was very important. The coping strategies and other protective practices they used to manage stress included heeding to experts' advice, seeking assistance, support, and encouragement from others, maintaining social contact with friends and relatives, and informal support for instance help from grandparents and other relatives. Prior research has 
reported that social relationships, services and support provided by society, as well as information seeking behaviour can aid with subsequent coping (Yan et al., 2021; Salin et al., 2020; Mosanya, 2020; Yan et al., 2021; Liu et al., 2017; 2019).

The results also showed that the majority of participants used spirituality to help them cope with the stress. They used religion and piety as an emotion-focused coping strategy. The participants and their families considered prayers essential for coping with the situation. This finding is congruent with existing literature which reported that religious social support provides emotional support during stressful times (Lorenz et al., 2019; Barrett, 2013).

The qualitative results indicate that the women used relationship or group-level coping strategies for mediating stress. These strategies included family time, agreements establishing daily routines and practices, cohesiveness or togetherness, strong marital relationship and positive family communication. strong marital relationship and emotional bonding. Therefore, the results of this study strongly support the arguments of previous researchers (e.g., Mariani et al., 2020; Mosanya, 2020, and Salin et al., 2020) that in order to better understand the coping strategies of families, we should take into account the social and cultural environment surrounding families, social relationships, and communication or exchanges between family members, perceived family support as well as decisions and attitudes of key family members. The presence of these significant relationships appeared to have alleviated emotional stress and helped manage feelings of loneliness (Mariani et al., 2020). Overall, the key aspect of this finding is perceived family support which is important because in Kuwait people have been compelled to stay at home during the lockdown, and therefore they have lived, in most cases, only with family members.

The present study's findings suggest that the effective use of family and resiliency resources can help families to adopt positive coping styles when experiencing stressful situations. 


\section{Conclusion}

The findings highlight stressors experienced by women in Kuwait and the approaches used by them to cope with stress during the COVID-19 crisis.

The contribution of this paper is founded on the fact that this study is conducted in the context of family stress during the COVID-19 pandemic in Kuwait where there is limited empirical evidence. The findings have significant implications for for policy, practice, theory, and subsequent research.

The data have practical implications for the design of interventions programmes. The perceptions of women regarding coping strategies are crucial for the success of the implementation of preventive strategies, as they are among the key stakeholders of prevention initiatives. Comprehensive assessments of the needs of women are important to plan appropriate interventions to alleviate their stress and strengthen their coping skills. The findings can inform health promotion efforts and future research on coping with stress. Collectively, the three broad strategies reported in this study need to be developed into a cohesive and comprehensive intervention.

There are some limitations regarding the study's sample size, thus the above research findings cannot be generalized to the general population. Further research employing larger and more representative samples could shed more light on the investigated issues.

\section{Declarations}

Funding: The authors declare that there are no relevant or material financial interests or non-financial interests related to this research.

Conflicts of interest/Competing interests: The authors have no conflicts of interest to declare that are relevant to the content of this article. 
- Using Family Resources as a Coping Strategy to Manage Stress During the COVID-19 Pandemic

\section{References}

- Al Dhaheri, A.S., Bataineh, M.F., Mohamad, M.N., Ajab, A., Al Marzouqi, A., et al. (2021) Impact of COVID-19 on mental health and quality of life: Is there any effect? A cross-sectional study of the MENA region. PLOS ONE. 16(3), e0249107. https://doi.org/10.1371/journal.pone.0249107

- Allen, M. (2017). The Sage Encyclopaedia of Communication Research Methods (Vols. 1-4). Thousand Oaks, CA: SAGE Publications https://doi.org/10.4135/9781483381411

- Alsharji, K.E. Anxiety and depression during the COVID-19 pandemic in Kuwait: the importance of physical activity. Middle East Current Psycholog. 27, 60 (2020). https://doi.org/10.1186/s43045-020-00065-6

- Barrett, C. (2013) Religious Social Support. In: Gellman M.D., Turner J.R. (eds) Encyclopedia of Behavioral Medicine. Springer, New York, NY. https://doi.org/10.1007/978-1-4419-1005-9_1593

- Barzilay, R., Moore, T.M., Greenberg, D.M. et al. (2020). Resilience, COVID19-related stress, anxiety and depression during the pandemic in a large population enriched for healthcare providers. Transl Psychiatry 10, 291 https://doi.org/10.1038/s41398-020-00982-4

- Berardi, L., Glantsman, O., \& Whipple, C. (2019). Stress and Coping. In: Jason L, Glantsman O, O'Brien J, Ramian K (Editors). Introduction to Community Psychology: Becoming an Agent of Change. Creative Commons.

- Boss P. (2014) Family Stress. In: Michalos A.C. (eds) Encyclopedia of Quality of Life and Well-Being Research. Springer, Dordrecht. https://doi.org/10.1007/978-94-007-0753-5_1008

- Brown, S. M., Doom, J. R., Lechuga-Peña, S., Watamura, S. E., \& Koppels, T. (2020). Stress and parenting during the global COVID-19 pandemic. Child Abuse \& Neglect, 110(2), 104699. https://doi.org/10.1016/j.chiabu.2020.104699

- Cao, W., Fang, Z., Hou, G., Xu, X., Dang, J., \& Zheng, J. (2020). The psychological impact of the COVID-19 epidemic on college students in China. Psychiatry Research, 287. https://doi.org/10.1016/j.psychres.2020.112934 
- Chauhan, P. (2020). Gendering COVID-19: Impact of the Pandemic on Women's Burden of Unpaid Work in India. Gender Issues https://doi.org/10.1007/s12147-020-09269-w

- Del Boca, D., Oggero, N., Profeta, P. et al. (2020). Women's and men's work, housework and childcare, before and during COVID-19. Rev Econ Household 18, 1001-1017 https://doi.org/10.1007/s11150-020-09502-1

- Donald J.N., \& Atkins P.W.B. Mindfulness and coping with stress: Do levels of perceived stress matter? Mindfulness, 7(6), 1423-1436. https://doi.org/10.1007/s12671-016-0584-y

- Faccio F, Renzi C, Giudice AV and Pravettoni G (2018) Family Resilience in the Oncology Setting: Development of an Integrative Framework. Frontiers in Psychology. 9, 666. https://doi.org/10.3389/fpsyg.2018.00666

- Fegert, J.M., Vitiello, B., Plener, P.L. et al. (2020). Challenges and burden of the Coronavirus 2019 (COVID-19) pandemic for child and adolescent mental health: a narrative review to highlight clinical and research needs in the acute phase and the long return to normality. Child and Adolescent Psychiatry and Mental Health 14, 20 https://doi.org/10.1186/s13034-020-00329-3

- Friedline, T., Chen, Z. \& Morrow, S. (2020). Families' Financial Stress \& WellBeing: The Importance of the Economy and Economic Environments. Journal of Family and Economic Issues https://doi.org/10.1007/s10834-020-09694-9

- Galica, J., Liu, Z., Kain, D. et al. (2021). Coping during COVID-19: A mixed methods study of older cancer survivors. Support Care Cancer 29, 3389-3398 https://doi.org/10.1007/s00520-020-05929-5

- Garbóczy, S., Szemán-Nagy, A., Ahmad, M.S. et al. (2021). Health anxiety, perceived stress, and coping styles in the shadow of the COVID-19. BMC Psychology, 9, 53 https://doi.org/10.1186/s40359-021-00560-3

- García, F.E., Barraza-Peña, C.G., Wlodarczyk, A. et al. (2018). Psychometric properties of the Brief-COPE for the evaluation of coping strategies in the Chilean population. Psicologia: Reflexão e Crítical Psychology: Research and Review 31, 22 https://doi.org/10.1186/s41155-018-0102-3

- Harris, G., Greene, K., Chavez, F. L. C. (2019). Family Stress, Coping, and Resilience: Challenges and Experiences of Modern Families. Kendall Hunt Publishing. 
- Henry, C. S., Hubbard, R. L., Struckmeyer, K. M., \& Spencer, T. A. (2018). Family resilience and caregiving. In W. A. Bailey \& A. W. Harrist (Eds.), Family caregiving (pp.1-26). Cham: Springer.

- Janssen, L.H.C., Kullberg, M.J., Verkuil, B., van Zwieten, N., Wever, M.C.M., van Houtum, L.A.E.M., et al. (2020) Does the COVID-19 pandemic impact parents' and adolescents' well-being? An EMA-study on daily affect and parenting. $\quad P L o S \quad O N E \quad$ 15(10), 0240962. https://doi.org/10.1371/journal.pone.0240962

- Kocalevent, RD., Zenger, M., Hinz, A. et al. (2017). Resilient coping in the general population: standardization of the brief resilient coping scale (BRCS). Health Qual Life Outcomes 15, 251 https://doi.org/10.1186/s12955017-0822-6

- Kubb, C., \& Foran, H.M. (2020) Measuring COVID-19 Related Anxiety in Parents: Psychometric Comparison of Four Different Inventories JMIR Mental Health 7(12) https://doi.org/10.2196/24507

- Larsson, A., Hooper, N., Osborne, L. (2016). Using Brief Cognitive Restructuring and Cognitive Defusion Techniques to Cope with Negative Thoughts. Sage Journals, Behavior Modification 40 (3), 452-482. https://doi.org/10.1177/0145445515621488

- Levin, M.E., An, W., Davis, C.H., \& Twohig, M.P. (2020). Evaluating Acceptance and Commitment Therapy and Mindfulness-Based Stress Reduction Self-Help Books for College Student Mental Health. Mindfulness. 11, 12751285 .

- Little B. (2018) Passive Coping Strategies. In: Zeigler-Hill V., Shackelford T. (eds) Encyclopedia of Personality and Individual Differences. Springer, Cham. https://doi.org/10.1007/978-3-319-28099-8_1867-1

- Liu, J.J.W., Ein, N., Gervasio, J., \& Vickers, K. (2019). The efficacy of stress reappraisal interventions on stress responsivity: A meta-analysis and systematic review of existing evidence. PLoS ONE, 14, e0212854. https://doi.org/10.1371/journal.pone.0212854

- Liu, J.J.W, Vickers, K., Reed, M., \& Hadad, M. (2017). Re-Conceptualizing stress: Shifting views on the consequences of stress and its effects on stress 
reactivity.

PLoS

ONE

12(3):

e0173188..

https://doi.org/10.1371/journal.pone.017318

- Liu, J. J. W., Reed, M., Vickers, K. (2019). Reframing the individual stress response: Balancing our knowledge of stress to improve responsivity to stressors. Stress Health. 35(5), 607-616. https://doi.org/10.1002/smi.2893.

- Loeb, S., Dynarski, S., McFarland, D., Morris, P., Reardon, S., \& Reber, S. (2017). Descriptive analysis in education: A guide for researchers. (NCEE 2017-4023). Washington, DC: U.S. Department of Education, Institute of Education Sciences, National Center for Education Evaluation and Regional Assistance [Online] Retrieved from https://files.eric.ed.gov/fulltext/ED573325.pdf

- Lorenz, L., Doherty, A., \& Casey, P. (2019). The role of religion in buffering the impact of stressful life events on depressive symptoms in patients with depressive episodes or adjustment disorder. International Journal of Environmental Research and Public Health, 16(7), 1238.

- Mariani R, Renzi A, Di Trani M, Trabucchi G, Danskin K and Tambelli R (2020) The Impact of Coping Strategies and Perceived Family Support on Depressive and Anxious Symptomatology During the Coronavirus Pandemic (COVID-19) Lockdown. Front. Psychiatry 11:587724. doi: 10.3389/fpsyt.2020.587724

- Martínez-Montilla, J.M., Amador-Marín , B., \& Guerra-Martín, M.D. (2017). Family coping strategies and impacts on family health: A literature review, Enfermeria Global, 47, 592-604 http://dx.doi.org/10.6018/eglobal.16.3.255721

- McCubbin, H. I., McCubbin, M. A., Thompson, A. I., \& Thompson, E. A. (1998). Resiliency in ethnic families: A conceptual model for predicting family adjustment and adaptation. In H. I. McCubbin, E. A. Thompson, A. I. Thompson, \& J. E. Fromer (Eds.), Resiliency in families series, Vol. 2. Resiliency in Native American and immigrant families (p. 3-48). Sage Publications, Inc.

- McCubbin, M. A., \& McCubbin, H. I. (1996). Resiliency in families: A conceptual model of family adjustment and adaptation in response to stress and crises. In H. I. McCubbin, A. I. Thompson, \& M. A. McCubbin (Eds.), Family 
assessment: Resiliency, coping and adaptation: Inventories for research and practice (pp. 1-64). Madison, WI: University of Wisconsin, Madison.

- McCubbin, H. I.,. Olson, D. H., \& Larsen, A. S. (1991). F-COPES: Family Crisis Oriented Personal Evaluation Scales, In: H. I. McCubbin and A. I. Thompson (Eds). Family Assessment Inventories for Research and Practice, pp. 203-218, University of Wisconsin-Madison, Madison, Wis, USA, 2nd edition.

- McCubbin, H.I., Thompson, A.I., \& McCubbin, M.A. (1996). Family assessment: resiliency, coping and adaptation: inventories for research and practice. Madison: University of Wisconsin System.

- Mosanya, M. (2020). Buffering Academic Stress during the COVID-19 Pandemic Related Social Isolation: Grit and Growth Mindset as Protective Factors against the Impact of Loneliness International Journal of Applied Positive Psychology https://doi.org/10.1007/s41042-020-00043-7

- Mosley, E., \& Laborde, S. (2015) Performing under Pressure: Influence of Personality- Trait-Like Individual Differences In M. Raab, B. Lobinger, S. Hoffman, A. Pizzera \& S. Laborde. Performance Psychology: Perception, Action, Cognition, and Emotion (pp.291-314) Elsevier https://doi.org/10.1016/B978-0-12-803377-7.00018-1

- Ogueji, I.A., Okoloba, M.M. \& Demoko Ceccaldi, B.M. (2021). Coping strategies of individuals in the United Kingdom during the COVID-19 pandemic. Current Psychology https://doi.org/10.1007/s12144-020-01318-7

- Pisano, L., Galimi, D., \& Cerniglia, L. (2020, April 13). A qualitative report on exploratory data on the possible emotional/behavioral correlates of Covid-19 lockdown in 4-10 years children in Italy. Psyarxiv https://doi.org/10.31234/osf.io/stwbn

- Polizzi, C., Lynn, S.J., Perry, A. (2020). Stress and Coping in the Time of COVID-19: Pathways to Resilience and Recovery. Clinical Neuropsychiatry, 17 (2), 59-62. https://doi.org/10.36131/CN20200204

- Price, S., Price, C., McKenry, P. ( 2020). Families Coping With Change: A Conceptual Overview. In: Bush, K.R., \& Price, C. A. (Eds.). Families and change: Coping with stressful events and transitions ( $6^{\text {th }}$ ed.). Thousand Oaks, CA: SAGE Publications, Inc. 
مجلة بحوث التريية النوعية - علد \& - أكتوير

- Randall, A.K., \& Bodenmann, G. (2013) Family Stress. In: Gellman M.D., Turner J.R. (eds) Encyclopedia of Behavioral Medicine. Springer, New York, NY. https://doi.org/10.1007/978-1-4419-1005-9_17

- Salin, M., Kaittila, A., Hakovirta, M., \& Anttila, M. (2020). Family Coping Strategies During Finland's COVID-19 Lockdown Sustainability 12, 9133. https://doi.org/10.3390/su12219133

- Saravanan C, Mahmoud I, Elshami W and Taha MH (2020) Knowledge, Anxiety, Fear, and Psychological Distress About COVID-19 Among University Students in the United Arab Emirates. Frontiers in. Psychiatry 11:582189. https://doi.org/10.3389/fpsyt.2020.582189

- Shamblaw, A. L., Rumas, R. L., \& Best, M. W. (2021). Coping during the COVID-19 pandemic: Relations with mental health and quality of life. Canadian Psychology/Psychologie canadienne, 62(1), 92-100. http://dx.doi.org/10.1037/cap0000263

- Shechter, A.; Diaz, F.; Moise, N.; Anstey, E.; Ye, S.; Agarwal, S.; Birk, J.L.; Brodie, D.; Cannone, D.; Chang, B.; et al. (2020). Psychological distress, coping behaviors, and preferences for support among New York healthcare workers during the COVID-19 pandemic. General Hospital Psychiatry, 66, 1-8.

- Shuwiekh, H.A., Kira, I.A., Sous, M.S.F. et al. The differential mental health impact of COVID-19 in Arab countries. Current Psychology. 1-15. https://doi.org/10.1007/s12144-020-01148-7.

- Scult, M.A., Knodt, A.R., Swartz, J.R., Brigidi, B.D., \& Hariri, A.R. (2017). Thinking and feeling: Individual differences in habitual emotion regulation and stress-related mood are associated with prefrontal executive control. Clinical Psychological Science. 5, 150-157.

- Spinelli, M., Lionetti, F., Pastore, M., \& Fasolo, M. (2020) Parents' Stress and Children's Psychological Problems in Families Facing the COVID-19 Outbreak in Italy. Frontiers in Psychology. 11, 1713. https://doi.org/10.3389/fpsyg.2020.01713

- Tahara, M., Mashizume, Y., Takahashi, K. (2021). Coping Mechanisms: Exploring Strategies Utilized by Japanese Healthcare Workers to Reduce Stress and Improve Mental Health during the COVID-19 Pandemic. International 
Journal of Environmental Research in Public Health, 18, 131. https:// dx.doi.org/10.3390/ijerph18010131

- Walsh F. (2016). Family resilience: a developmental systems framework. European Journal of Developmental Psychology, 3, 313-324.

- Wang, C. (2020). To Cope with a New Coronavirus Pandemic: How Life May Be Changed Forever, Chinese Journal of International Law, 19(2), 221228, https://doi.org/10.1093/chinesejil/jmaa020

- Wang, X., \& Cheng, Z. (2020). Cross-Sectional Studies: Strengths, Weaknesses, and Recommendations Supplement: An Overview of Study Design and Statistical Considerations, CHEST Journal, 158(1), https://doi.org/10.1016/j.chest.2020.03.012

- Wang, C., Pan, R., Wan, X., Tan, Y., Xu, L., Ho, C., \& Ho, R. (2020). Immediate psychological responses and associated factors during the initial stage of the 2019 coronavirus Disease (COVID-19). Epidemic among the General Population in China. International Journal of Environmental Research and Public Health, 17, 1729. https://doi.org/10.3390/ijerph1705172

- Wasil, A. R., Venturo-Conerly, K. E., Gillespie, S., Osborn, T. L., and Weisz, J. R. (2021). In their own words: using open-ended assessment to identify culturally relevant concerns among Kenyan adolescents. Culture, Medicine and Psychiatry https://doi.org/10.1007/s11013-020-09706-1

- Wenham, C., Smith, J., \& Morgan, R. (2020). COVID-19: The Gendered Impacts of the Outbreak, Lancet Publishing Group, http://dx.doi.org/10.1016/S0140-6736(20)30526-2

- Williams, S. N., Armitage, C. J., Tampe, T., et al. (2020). Public perceptions and experiences of social distancing and social isolation during the COVID-19 pandemic: A UK based focus group study. BMJ Open, 10, e039334. https://doi.org/10.1136/bmjopen-2020-039334

- Wu, Y., Yu, W., Wu, X. et al. (2020). Psychological resilience and positive coping styles among Chinese undergraduate students: a cross-sectional study. BMC Psychology. 8, 79 https://doi.org/10.1186/s40359-020-00444-y

- Yan, S., Xu, R., Stratton, T.D. et al. Sex differences and psychological stress: responses to the COVID-19 pandemic in China. BMC Public Health 21, 79 (2021). https://doi.org/10.1186/s12889-020-10085-w 